\title{
A Study of Correlation between Proteinuria and Histological Findings in Lupus Nephritis Patient
}

\author{
Md. Golam Faruk ${ }^{1}$, Anwarul Kibria ${ }^{1}$, Mahfuzul Quader ${ }^{1}$, Mahtab Uddin Hasan ${ }^{2}$, \\ M.A.Hassan Chowdhury ${ }^{3}$, Sujat Paul ${ }^{4}$, Mohammad Nezam Uddin ${ }^{5}$, Ratan \\ Kumar Nath ${ }^{6}$,Kamrul Hasan Lohani ${ }^{6}$, Mohammed Rezaul Karim ${ }^{7}$, \\ Mahfuzur Rahman Babul ${ }^{8}$, M.S.Haider ${ }^{9}$, Mizanur Rahman ${ }^{10^{*}}$ \\ ${ }^{I}$ Department of Anatomy, Chittagong Medical College, Chittagong, Bangladesh \\ ${ }^{2}$ Principal and Head, Department of Medicine, Marine City Medical College, Chittagong, Bangladesh \\ ${ }^{3}$ Director, Bangladesh Institute of tropical medicine and infectious disease, Chittagong, Bangladesh \\ ${ }^{4}$ Department of Medicine, Chittagong Medical College Hospital, Chittagong, Bangladesh \\ ${ }^{5}$ Medical Director, Treatment Hospital, Chittagong, Bangladesh \\ ${ }^{6}$ Department of Pharmacology, Chittagong Medical College, Chittagong, Bangladesh \\ ${ }^{7}$ Bilaichary Upazilla Health Complex, Rangamati Hill Tract, Bangladesh \\ ${ }^{8}$ Medical Assistant Training School, Noakhali, Bangladesh. \\ ${ }^{9}$ Chittagong General Hospital, Chittagong, Bangladesh. \\ ${ }^{10}$ Department of Biochemistry, Rangamati Medical College, Rangamati, Bangladesh.
}

\begin{abstract}
Systemic Lupus Erythematosus (SLE) is a multisystem auto-immune disease with wide spectrum of clinical and immunological abnormalities including development of auto-antibodies against DNA and other nuclear antigen. All organ tissues may be involved but the skin, joints, heart, nervous system and kidneys are most commonly affected. Clinical evidence of renal disease occurs in 40 to $75 \%$ of patients with SLE. The persistent proteinuria is the most frequent sign of the LN (Lupus Nephritis) and occurs in $70 \%$ of patients. A study was done involved 30 patients of Lupus Nephritis hospitalized in the Nephrology department of Chittagong Medical College Hospital, Chittagong, Bangladesh, between May 2010 to April 2011 to find correlation between proteinuria and the histological type of Lupus Nephritis. Dependent variable like proteinuria and independent variables like different histological types were analyzed by chi ${ }^{2}$, ANOVA and Pearson's correlations test. All patients was found female. Average age of patient was $27.17+9.51$ years. Positive ANA titre was found in 77\% of patient and positive Anti Ds DNA titre in $100 \%$ of patients. Common histological type was found class IV. We had found a positive correlation between the values of proteinuria with histological classes of Lupus Nephritis.
\end{abstract}

Keywords: Proteinuria, Lupus Nephritis (LN), Systemic Lupus Erythematosus (SLE), Anti nuclear Antibody (ANA)

\section{Introduction}

SLE is an autoimmune multi-system disease with different clinical and immunological manifestations, characterized by presence of anti-nuclear antibodies.[1,2] Renal involvement in SLE occurs in 40-75 percent of patients most frequently in a period of 5 years after the onset of the disease. It is one of the strongest predictors of poor outcome. Renal glomeruli are the main structures affected by immune complex deposits[2].The clinical manifestations of the renal involvement occurs in 50 percent of patients and depends on the histological type of Lupus nephritis. The persistent proteinuria is the most frequent findings of Lupus nephritis and occurs in 70 percent of patients. Hematuria occurs in 40 percent of patients and azotemia in 30 percent. A proteinuria< 1 $\mathrm{gm} /$ day occurs in mesangial glomerulonephritis [3]. Proteinuria between 1-3 gm/day usually occurs in focal or diffuse glomerulonephritis and proteinuria > $3 \mathrm{gm} /$ day occurs in membranous or diffuse proliferative glomerulonephritis [3].

Nephritis is usually the most serious manifestation of SLE, particularly nephritis and infections were the leading causes of mortality in the first decade of disease. Since nephritis is asymptomatic in most Lupus nephritis patient, urinalysis should be done in any person of clinical SLE. The classification of Lupus nephritis is primarily histological. Renal biopsy is useful in planning effective therapy. Patients with dangerous proliferative forms of glomerular damage ISN III and IV usually have microscopic hematuria and proteinuria (> $500 \mathrm{mg} /$ day). Approximately one half develop nephritic syndrome and most develops hypertension. If diffuse proliferative glomerulonephritis (DPGN) is untreated virtually all patients develops End Stage Renal Disease (ESRD) within 2 years of diagnosis. Therefore aggressive immune suppression is indicated (usually systemic corticosteroid plus cytotoxic drugs) unless damage is irreversible. African American is more likely to develop 
ESRD than are Caucasians even with the most recommended therapies. Overall in the United States 20 percent of individuals with Lupus DPGN die or develop ESRN within 10 years of diagnosis. Such individual require aggressive control of SLE and of the complications of renal disease and of therapy. A small proportion of SLE patient with proteinuria usually (Nephrotic) have membranous glomerular changes without proliferation on renal biopsy. Their outcome is better than those with DPGN but proteinuria is less likely to improve in Lupus nephritis without immune suppressive therapy. Lupus nephritis tends to be on going disease with flares requiring retreatment over many years. For most people with Lupus nephritis developed accelerated atherosclerosis after several years of disease. So attention must be given to control of blood pressure, hyperlipidaemia and hyperglycaemia [4] The clinical manifestations of kidney disease vary in SLE. Renal involvement develops concurrently or shortly following the onset of SLE in non-Caucasian population [5].

\section{Pathophysiology:}

Autoimmunity plays a major role in the pathogenesis of Lupus nephritis. The immunologic mechanisms include production of auto antibodies directed against nuclear elements. The characteristics of the nephritogenic auto antibodies associated with Lupus nephritis are as follows [6]. Antigen specificity directed against nucleosome or double-stranded DNA (ds DNA). Some anti-ds DNA antibodies cross-react with the glomerular basement membrane. Higher-affinity auto antibodies may form intravascular immune complexes, which was deposited in glomeruli. Cationic auto-antibodies have a higher affinity for the anionic glomerular basement membrane.

Auto antibodies of certain isotypes (immunoglobulin [Ig]G1 and [Ig]G3) readily activate complement. These auto antibodies form pathogenic immune complex intravascularly; which was deposited in glomeruli. Alternatively, auto antibodies may bind to antigens already located in the glomerular basement membrane, forming immune complexes in situ. Immune complexes promote an inflammatory responses by activating complement and attracting inflammatory cells, including lymphocytes, macrophages, and neutrophils [7,8].

The histologic type of Lupus nephritis that develops depends on numerous factors, including the antigen specificity and other properties of the auto antibodies and the type of inflammatory response that is determined by other host factors. In more severe forms of Lupus nephritis, proliferation of endothelial, mesangial, and epithelial cells and the production of matrix proteins lead to fibrosis [9].Glomerular thrombosis is another mechanism that may play a role in pathogenesis of Lupus nephritis, mainly in patients with anti phospholipid antibody syndrome, and is believed to be the result of antibodies directed against negatively charged phospholipid -protein complexes [7].

Six forms of clinical manifestations are encountered in patient with Lupus nephritis.

1) Dominant feature is proteinuria. 2) Acute or chronic renal failure. However reduced glomerular filtration rate is an uncommon occurrence within the first year except in non Caucasian population. 3) Acute Nephritic syndrome may occur with or without renal failure, particularly in proliferative forms of LN. 4) Rapidly progressive glomerulonephritis (RPGN). 5) Nephrotic syndrome which may be a features of membranous (Class V) or membrano-proliferative LN. 6) Thrombotic micro-angiopathies such as thrombotic thrombocytopenic purpura or haemolytic-uramic syndrome, anti-cardiolipin syndrome. Renal vein thrombosis and malignant hypertension may be superimposed on severe glomerulonephritis.

These clinical renal manifestations have a simplified frame work; however in most patients the non renal clinical features may dominate the clinical presentations [10]. Although histologically more severe glomerular forms of nephritis have a tendency to result in more severe manifestations, renal histology cannot be predicted with any certainty from the clinical picture. Patient who have received some immune-suppressants will almost certainly alter the serologic results [11].

Michael Kashgarian observed that patients with similar degree of disease activity and biopsy findings who experienced a longer interval between disease onset and biopsy had poorer long term outcomes [12]. The rate of deterioration in serum creatinine and 24 hours urinary total protein from disease onset to renal biopsy correlated with the activity and chronicity indices. This analysis suggests the early treatment of patient with a Class IV lesion with abundant sub endothelial deposits on a biopsy is of benefit.

The nature of the lesion in renal biopsy gives information relating to the severity of the autoimmune response within the kidney, there by aiding in predicting both short term and long term out comes. One study done by Viorica Crisan in the nephrology department of CHU Amiens, France between 2000-2004 about to identifying the clinical and biological aspects in Lupus nephritis and to find correlation between these and the histological type of Lupus nephritis[13]. By analyzing the clinical and biological signs of the renal involvement at onset they have found a strong association between the values of proteinuria, haematuria, and the hypertension with a worse class of LN [14]. The study showed minimal values of proteinuria were found in type II of LN and the highest values of proteinuria were found in type V of LN. All patients with favorable evolution achieved clinical remission that demonstrated the importance of the earlier diagnosis of LN by kidney biopsy and the earlier starting of treatment with pulse therapy. (NIH in USA and European trial in Europe)[15-17]. 
In the present study a positive correlation was found between proteinuria and histological classes in Lupus nephritis patient. When renal biopsy cannot possible due to any reason (like any contra-indication, poverty of patient, if patient refuses, any co- morbid condition, or lack of facilities in remote areas), severity of renal damage (histological class) can be assessed by measuring the proteinuria. Increased levels of proteinuria indicate more severe histological classes of Lupus Nephritis.

\section{Materials And Method}

An observational cross sectional study was done at Medicine and Nephrology department of Chittagong medical college hospital, Chittagong, Bangladesh from May 2010 to April 2011. Inclusion criteria were SLE patients having proteinuria $>500 \mathrm{mg}$ / day and age $15-55$ years. Exclusion criteria were a)Lupus nephritis patients with co-morbid condition such as ESRD, CNS, and other vital organ involvement, DM, pregnancy, HIV disease etc,b)Lupus nephritis with contraindications for renal biopsy such as bleeding disorder, solitary kidney,un-controlled hypertension etc, c)Patients having ascitis, jaundice and positive HbsAg, CLD etc,b)Any treatment that may modify levels of proteinuria such as treatment by immune-suppressive and steroid drugs and e)Patient refuses to do biopsy.

Sixty diagnosed case of SLE was included in the study. All patients were informed about the aims and objectives of the study including risks and benefits of the study procedure with all investigations before enrollment. They were encouraged for voluntary participation and gave freedom to withdraw from the study at any time without any hesitation. Then forty two patients with renal involvement were selected by taking history, doing clinical examination and investigation. 24 hours urinary total protein estimation was done in all these patients to quantify urine protein loss. Urine was collected in plastic container with preservative and kept in cool place during collection. The container sends to pathological laboratory as early as possible after completion of urine collection. Thirty six patients having 24 hours urine protein loss $>500 \mathrm{mg} / \mathrm{day}$ were selected and finally thirty two patients were selected for biopsy by selection criteria.

\section{Data Collection}

All relevant information for each individual study subject was recorded on a pre-tested data sheet. Collected data were checked repeatedly. Data was processed and analysis was done by expert statistician using computer based software SPSS-19 (Chicago, Illinois, USA). Discrete or qualitative variables like gender, age group, histological types etc were analyzed by Chi-square test and Pearson's correlations test. Continuous variables like age, levels of proteinuria were analyzed by ANOVA test. P value was considered as statistically significant when it is less than 0.05 .

\section{Results}

Table-01: Distribution of clinical variables $(\mathrm{n}=30)$

\begin{tabular}{|l|l|l|l|}
\hline \multicolumn{2}{|l|}{ Clinical Variables } & Frequency & Percentage (\%) \\
\hline \multirow{3}{*}{ Anaemia } & Mild & 22 & 73.3 \\
\cline { 2 - 4 } & Moderate & 6 & 20.0 \\
\cline { 2 - 4 } & Nil & 2 & 6.7 \\
\hline \multirow{2}{*}{ Oedema } & Present & 27 & 90.0 \\
\cline { 2 - 4 } & Absent & 3 & 10.0 \\
\hline \multirow{2}{*}{ Hypertension } & Present & 12 & 40.0 \\
\cline { 2 - 4 } & Absent & 18 & 60.0 \\
\hline Total & $\mathbf{3 0}$ & $\mathbf{1 0 0 . 0}$ \\
\hline
\end{tabular}

Table - 02 : Distribution of urine examination findings $(\mathrm{n}=30)$

\begin{tabular}{|l|l|l|l|}
\hline Urine Examination Findings & Frequency & Percentage (\%) \\
\hline \multirow{5}{*}{ Proteinuria * } & Trace $(10$ to $20 \mathrm{mg} / \mathrm{dl})$ & 1 & 3.3 \\
\cline { 2 - 4 } & $+(30 \mathrm{mg} / \mathrm{dl})$ & 10 & 33.3 \\
\cline { 2 - 4 } & $++(100 \mathrm{mg} / \mathrm{dl})$ & 13 & 43.4 \\
\cline { 2 - 4 } & $+++(300 \mathrm{mg} / \mathrm{dl})$ & 6 & 20.0 \\
\cline { 2 - 4 } & $4+(1 \mathrm{~g} / \mathrm{dl})$ & 0 & 0.0 \\
\hline \multirow{5}{*}{ WBC } & Significant ** & 21 & 70.0 \\
\cline { 2 - 4 } & Not Significant & 5 & 16.7 \\
\cline { 2 - 4 } & Nil & 4 & 13.3 \\
\hline \multirow{5}{*}{ RBC } & Significant & 18 & 60.0 \\
\cline { 2 - 4 } & Not Significant & 7 & 23.3 \\
\cline { 2 - 4 } & Nil & 5 & 16.7 \\
\hline \multirow{5}{*}{ Casts } & Cellular & 5 & 6.7 \\
\cline { 2 - 4 } & Hyaline & 2 & 3.3 \\
\cline { 2 - 4 } & Granular & 22 & $\mathbf{1 0 0 . 0}$ \\
\cline { 2 - 4 } & Nil & $\mathbf{3 0}$ & \\
\hline Total & & & 13.3 \\
\hline
\end{tabular}


* Proteinuria was quantified according to the color combination by strip $(Y-19)$ method

** > 5 pus cells/HPF of centrifuged sample or > 10 pus cells/HPF of non-centrifuged urine

Table - 03: Distribution of total urinary protein grading $(\mathrm{n}=30)$

\begin{tabular}{|l|l|l|}
\hline Total Urinary Protein Grading & Frequency & Percentage (\%) \\
\hline $500 \mathrm{mg}-1 \mathrm{gm} /$ Day & 7 & 23.3 \\
\hline $1-2 \mathrm{gm} /$ Day & 9 & 30.0 \\
\hline $2-3 \mathrm{gm} /$ Day & 6 & 20.0 \\
\hline$>3 \mathrm{gm} /$ Day & 8 & 26.7 \\
\hline Total & $\mathbf{3 0}$ & $\mathbf{1 0 0 . 0}$ \\
\hline
\end{tabular}

Table - 04: Distribution of ANA and Ds DNA titres $(\mathrm{n}=30)$

\begin{tabular}{|l|l|l|l|}
\hline \multicolumn{2}{|l|}{ Titres } & Frequency & Percentage (\%) \\
\hline \multirow{2}{*}{ ANA Titre } & Positive & 23 & 76.7 \\
\cline { 2 - 4 } & Negative & 7 & 23.3 \\
\hline \multirow{2}{*}{ Ds DNA Titre } & Positive & 30 & 100.0 \\
\cline { 2 - 4 } & Negative & 0 & 0.0 \\
\hline \multicolumn{2}{|l|}{ Total } & $\mathbf{3 0}$ & $\mathbf{1 0 0 . 0}$ \\
\hline
\end{tabular}

Table - 05: Distribution of urinary total protein according to renal biopsy findings with ANOVA test significance $(\mathrm{n}=30)$

\begin{tabular}{|l|l|l|}
\hline Renal Biopsy Finding & $\mathbf{N}(\boldsymbol{\%})$ & Urinary Total Protein (gm/day) \\
\hline Class II & $5(16.6)$ & $1.66 \pm 0.56$ \\
\hline Class III & $8(26.7)$ & $1.47 \pm 0.99$ \\
\hline Class IV & $11(36.7)$ & $2.08 \pm \mathbf{1 . 2 0}$ \\
\hline Class V & $6(20.0)$ & $4.40 \pm 1.01$ \\
\hline Total & $\mathbf{3 0}$ & $\mathbf{2 . 3 1} \pm \mathbf{1 . 4 6}$ \\
\hline
\end{tabular}

* ANOVA Test Significance $: F=10.826 ; P=0.000 ;$ Highly Significant $(P<0.001)$

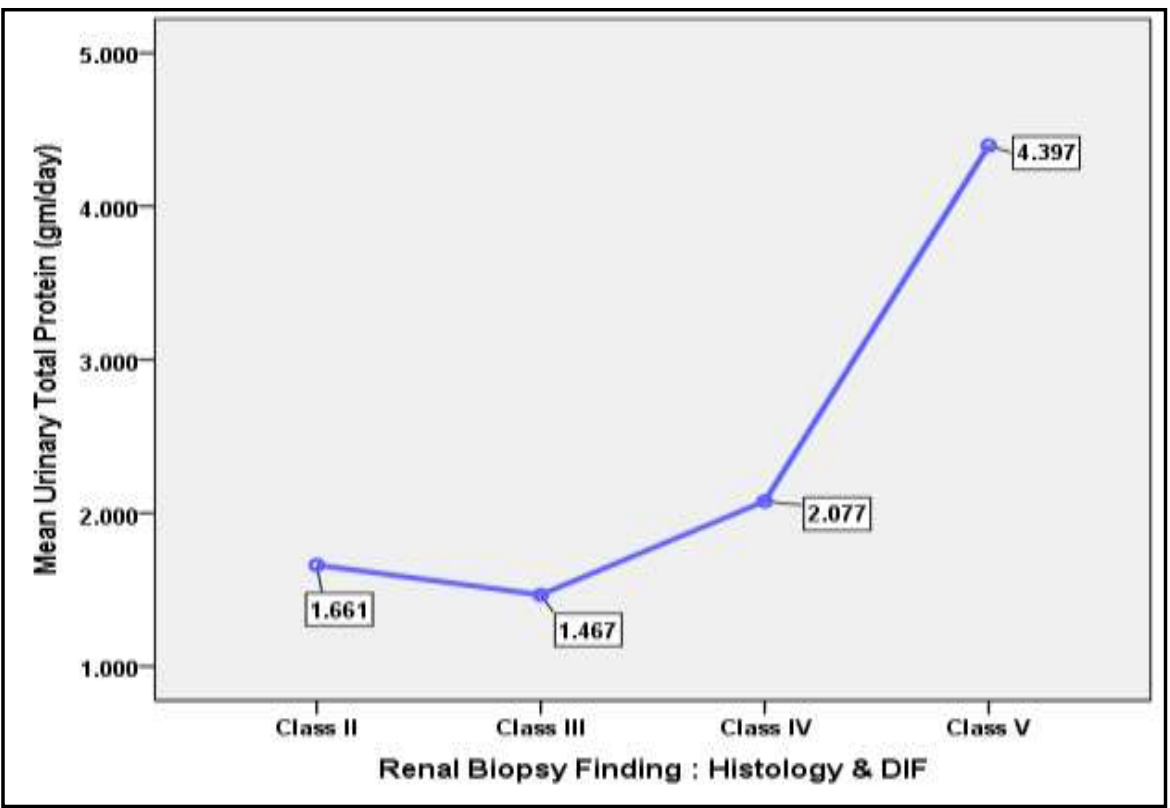

Figure: 1 Graph showing mean urinary total proteins according to renal biopsy findings.

Table - 06: Association between renal biopsy findings and proteinuria with Chi-square test significance $(n=$ 30)

\begin{tabular}{|l|l|l|l|l|l|l|}
\hline \multirow{2}{*}{ Renal Biopsy Finding } & \multicolumn{2}{|l|}{ Proteinuria } & \multirow{2}{*}{ Total } \\
\cline { 2 - 6 } \multicolumn{2}{|l|}{ Trace } & + & ++ & +++ & \\
\hline \multirow{2}{*}{ Class II } & 0 & 1 & 4 & 0 & 5 \\
\cline { 2 - 6 } Class III & 1 & 3 & 2 & 2 & 8 \\
\cline { 2 - 6 } Class IV & 0 & 6 & 4 & 1 & 11 \\
\cline { 2 - 6 } Class V & 0 & 0 & 3 & 6 & 6 \\
\hline \multicolumn{2}{|l|}{ Total } & 1 & 10 & 13 & 6 & 30 \\
\hline
\end{tabular}

$* \chi^{2}$ Test Significance $: \chi^{2}=13.354 ; P=0.147 ;$ Not Significant $(P>0.05)$ 


\begin{tabular}{|c|c|c|c|c|c|c|}
\hline \multirow[t]{6}{*}{$* \quad \chi^{2}$ Test } & & $\begin{array}{l}500 \mathrm{mg} \\
-1 \mathrm{gm} / \mathrm{day}\end{array}$ & 1 - 2 gm/day & 2 - 3 gm/day & $>3 \mathrm{gm} / \mathrm{day}$ & \\
\hline & Class II & 1 & 3 & 1 & 0 & 5 \\
\hline & Class III & 4 & 2 & 1 & 1 & 8 \\
\hline & Class IV & 2 & 4 & 3 & 2 & 11 \\
\hline & Class V & 0 & 0 & 1 & 5 & 6 \\
\hline & Total & 7 & 9 & 6 & 8 & 30 \\
\hline
\end{tabular}

Significance $: \chi^{2}=17.509 ; P=0.041 ;$ Significant $(P<0.05)$

$* \chi^{2}$ Test Significance $: \chi^{2}=17.509 ; P=0.041 ;$ Significant $(P<0.05)$

Table - 07: Pearson's correlation between renal biopsy finding and total urinary protein $(\mathrm{n}=30)$

\begin{tabular}{|l|l|l|}
\hline Correlation between & Correlation Coefficient & Significance * \\
\hline $\begin{array}{l}\text { Renal Biopsy Finding \& } \\
\text { Total Urinary Protein }\end{array}$ & Pearson's r $=+0.604$ & $\begin{array}{l}\mathrm{P}=0.000 \\
\text { Highly Significant }\end{array}$ \\
\hline
\end{tabular}

* Correlations are Significant at the 0.01 level (2-tailed)

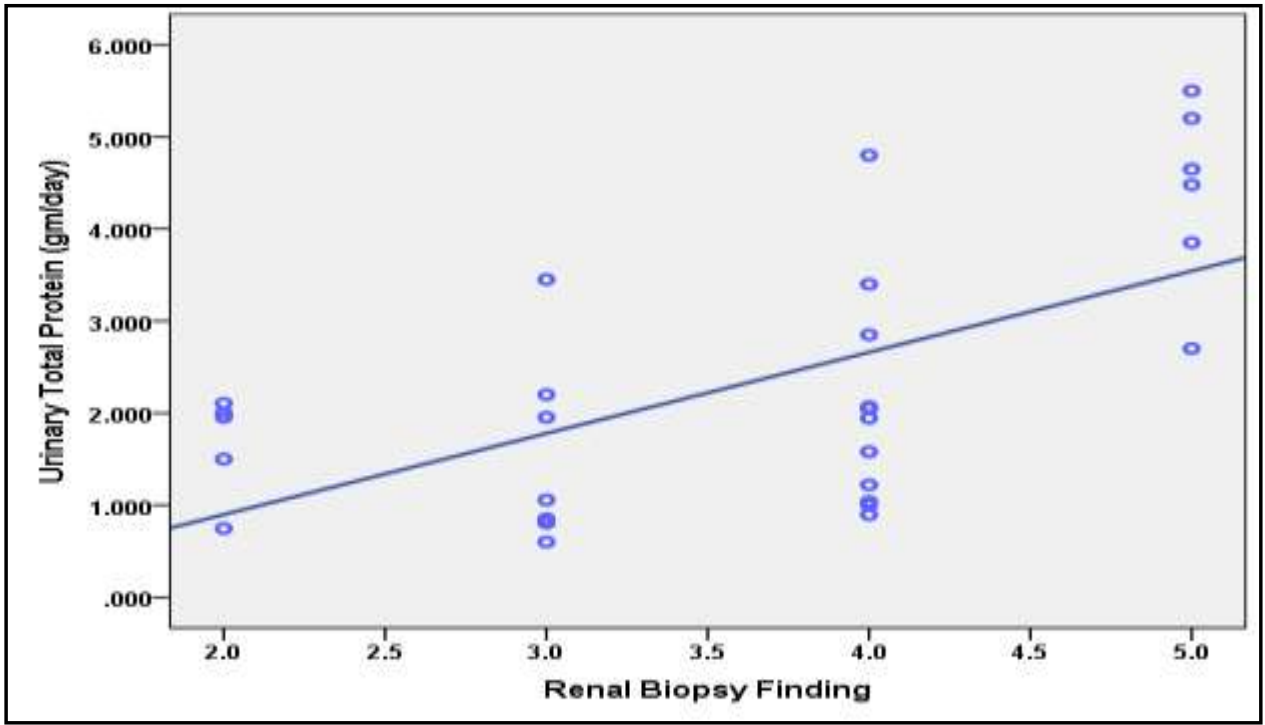

Figure:2 Scatter diagram showing positive correlation between renal biopsy finding and total urinary protein

The group was formed by 30 patients and all are found female. Most of the patients are in 20- 40 years. The mean age was $27.17+9.51$ years. The hematological modifications were represented by mild anemia in $73.3 \%$ and moderate anemia in $20 \%$. Oedema present in $90 \%$ patient and hypertension present in $40 \%$ patient. Highest number of patient (30\%) had proteinuria 1-2 gm/day. ANA were positive in 76.7\%, and the anti dsDNA antibodies in $100 \%$ of patients. Kidney biopsies indicated the following types of glomerulonephritis: type II in $16.6 \%$, type III in $26.7 \%$, type IV in $36.7 \%$, and type V in $20 \%$ of patients. Distribution of urinary total protein according to renal biopsy findings with ANOVA test was found highly significant. Pearson's correlation test between renal biopsy finding and total urinary protein was also found highly significant.

\section{Discussion}

This was a cross-sectional observational study of correlation between proteinuria and histological findings in 30 patients of Lupus Nephritis (LN) at Chittagong Medical College Hospital, Chittagong. In our study most common hematological abnormality was found anaemia which was found in 28 (93\%) patients. Various other studies have shown similar findings $[18,19]$. Iron deficiency anaemia, anaemia of chronic disease and auto-immune haemolytic anaemia may be the common causes of anaemia in these patients. Another clinical feature like oedema was found in $27(90 \%)$ of patients. As we have included lupus nephritis patients having proteinuria $>500 \mathrm{mg} /$ day in our study so oedema was commonly found in most of the patients. There is frequent 
association between hypertension and renal disease in SLE. In our study hypertension was present in $12(40 \%)$ patients. Other study had shown similar findings [20, 21]. In the study 24 hours urinary total protein estimation were done in all patients. Proteinuria $500 \mathrm{mg}$ to $1 \mathrm{gm} /$ day were found in 7 (23.3\%) patients, 1 to $2 \mathrm{gm} /$ day were found in $9(30 \%)$ patients, 2 to $3 \mathrm{gm} /$ day were found in $6(20 \%)$ patients, and $>3 \mathrm{gm} /$ day were found in $8(26 \%)$ patients. These findings are consistent with other study [22]. Renal biopsy findings of different classes were found significant in relation with level of proteinuria by ANOVA test $(\mathrm{P}<\mathrm{o} .001)$. It was similar with other study [14]. Renal biopsy findings of different classes were also found significant in relation with total urinary protein grading by Chi-square test $(\mathrm{P}<0.041)$, which was similar with other study [23]. In our study Pearson's correlation between renal biopsy findings and total urinary protein was found significant. $(\mathrm{P}$ value $=0.000)$. The most common criteria satisfied in SLE with lupus nephritis were positivity of ANA and anti Ds-DNA test. In our study $23(76.7 \%)$ patients were found ANA test positive where as all patients (n-30) were found anti DsDNA test positive. 7 (23.3\%) patients were found ANA negative. Regarding analysis of renal biopsy findings no patient were found in class-1 group. Most of the patients were in class-IV group which were found $11(36.7 \%)$. Class II group were found $6(16.6 \%)$, class III group were 8 (26.7\%) and class V group were 6 (20\%).These biopsy findings were similar other study [22].

\section{Conclusion}

Kidney involvement in systemic Lupus Erythematosus, known as Lupus nephritis (LN), is most often due to glomerular immune complex accumulation, which leads to glomerular inflammation and if unchecked also involves the renal interstitium. The kidney may also have sustained damage by other mechanism, such as thrombotic micro angiopathy. Lupus patient with LN have worse outcome than those with no kidney involvement [25] This poor prognosis is explained only in part by the risk of CKD and ESRD, suggesting that $\mathrm{LN}$ is a manifestation of a more severe form of systemic Lupus. Lupus nephritis usually develops within 3 years after diagnosis of SLE. However clinical data probably under estimate the prevalence of Lupus nephritis. Studies with renal biopsy showed that SLE involves the kidney in almost all cases in which enough tissue is available for analysis. Even in the absence of proteinuria or abnormal urinary sediment, the renal biopsy is rarely free of detectable abnormalities, especially if evaluated by immune-fluorescence or electron microscopy [26-28]. We have found a positive correlation between grading of proteinuria and histological classes in Lupus Nephritis patient. Increased level of proteinuria had found in the higher classes of Lupus Nephritis.

Disclosure:

All the authors declare no competing interest.

\section{References}

[1]. Alba P, Bento L, Caudrado MJ. Anti Ds-DNA, Anti-Sm antibodies, and the lupus anticoagulant: Significant factors associated with lupus nephritis. Ann Rheum Dis. 2003; 62:556-60.

[2]. Popesca E, Ionescu R. Systemic lupus erythematosus. In: Compendium of rheumatology. Bucharest: 2000; p. 117-33.

[3]. Popescu E, Ionescu R. Systemic lupus erythematosus. In: Textbook of internal medicine: Rheumatology. Vol. II: Medicala ed. Bucharest: 1999; p.1685-8.

[4]. Bevra Hannahs Hahn. Harrison's Principles of internal medicine, $16^{\text {th }}$ edition. Mc Graw-Hill, Medical publishing Division; New York: 2005; p. 1960-67.

[5]. Bastian Hm, Roseman JM, Mc Gwin G Jr. Systemic lupus erythematosus in three ethnic groups, XII. Risk factor for lupus nephritis after diagnosis. Lupus. 2002; 11: 152-160.

[6]. Yung S, Chan TM. Anti-DNA antibodies in the pathogenesis of Lupus Nephritis- the emerging mechanism. Auto-immune Rev. Feb 2008; (4):317-21.

[7]. D' Agati VD, Appel GB. Lupus Nephritis: Pathology and Pathogenesis. In: Wallace DJ, Hahn BH, eds. Dubois' Lupus Erythematosus. $7^{\text {th }}$ ed. Philadelphia, PA: Lippincott Williams and Wilkins; 2007:1094-111.

[8]. Grande JP. Mechanism of progression of renal damage in Lupus Nephritis: Pathogenesis of renal scarring. Lupus.1998; 7 (9):60410.

[9]. Rahman A, Isenberg DA. Systemic Lupus Erythematosus. N Engl J Med.Feb 28; 2008; 358 (9):929-39.

[10]. Berden JHM. Lupus nephritis: Nephrology forum. Kidney Int. 1997; 521: 538-558.

[11]. J. Stewart Cameron. Lupus Nephritis. J Am Soc Nephrol . 1999;10:413-424

[12]. Esdaile JM, Joseph L, Mackenzie T, Keshgarian M, Hayslett JP. The benefits of early treatment with immune-suppressive agents in lupus nephritis. J Rheumatol. Feb 2007; 34(2): 256-258

[13]. Viorican crisan. Lupus nephritis - clinical and therapeutical aspects. TMJ.2007; Vol. 57: no. 2-3, p. 141.

[14]. Viorican crisan. Lupus nephritis- clinical and therapeutical aspects. TMJ.2007; Vol.57: no.2-3, p.143-144.

[15]. Petri J. Combined oral contraceptive in women with SLE Eng. J Med. 2005; 353: 2550-49.

[16]. Chiu S J, OU L S, Tsai TL. Sequential evaluation of clinical and laboratory changes amongst children suffering from lupus nephritis during intermittent intravenous cyclophosphamide therapy. CI Rheum. 2005; 25 (4):515-9.

[17]. Breimler JHM, Andrassy K. Cyclophosphamide treatment in systemic necrotizing vasculitis and lupus nephritis, low, Long, low much. Ped Nephr. 2004;19: 949-55.

[18]. F Burling, J NG, H Thein, J LY MR Marshall' and P Gow. Lupus Around The World: Ethnic , clinical and immunological factors in systemic lupus erythematosus and the development of lupus nephritis: results from a multi-ethnic New Zealand cohort. Lupus. 2007; 16: 830-837.

[19]. Hahn BH. Systemic lupus Erythematosus: In Principles of Internal Medicine 2 . Brounwald E, Isselbach KJ, Petersdorf P G(ed.) $11^{\text {th }}$ ed. New York: McGraw Hill Book Company; p. 1418-1423. 
[20]. Indiran P, Naiker. The significance of arterial hypertension at the onset of clinical lupus nephritis. Postgrad Med. The Fellow ship of postgraduate medicine.1997; 73: 230-233.

[21]. Hurtado A, Asato C. Escudero E . Clinico-pathologic correlation in lupus nephritis in Lima, Peru. Nephrology .1999; 83: 323-330.

[22]. Nintin M, Gadgil . Clinical, morphological, immunological correlation of kidney biopsies and prognostication. Indian J Pathol Microbial. 1999; 42 (1): 3-10. p.9.

[23]. Mc curdy DK, Lchman TAI, Bernstein M. Lupus nephritis: prognostic factor in children. Pediatrics. 1992; 89: $240-6$.

[24]. Esdaile J M, Mackensie T, Barre P, Danott D, Osterland CK, Somerville P, et al. Can experienced clinicians predict the outcome of lupus nephritis. Lupus. 1992; 1:205-214

[25]. Eknoyan G, Lameire N. Kidney international supplements (2012)2: 586-588.Available from:221-232;doi:10.1038/k isup.2012.25[Accessed10/6/2016].

[26]. CavalloT,Cameron WR, and Lapenas D.Immunopathology of early and clinically silent Lupus Nephropathy. American Journal of Pathology.1977; 87:1-15.

[27]. Mahajan S K, (1987). Lupus Nephropathy without clinical renal involevement. Medicine.1987; 54: 493-501.

[28]. Font J,Torras A, Cervera R, Darnell A, Rovert L, and Ingelmo M. Silent renal disease in systemic lupus erythematosus. Clinical Nephrology.1987; 27: 79-84. 